\title{
El escepticismo filosófico de don Juan Valera
}

\author{
M. FERNANDo VARELA IGLESIAS \\ Universidad de Viena
}

En la Introducción a la novela Las ilusiones del doctor Faustino presenta Valera un curioso personaje, don Juan Fresco (trasunto de su autor, como veremos más adelante), cuyo originalísimo ideario filosófico, equidistante entre el positivismo empírico y la especulación metafísica, constituye la mejor introducción al pensamiento de Valera:

Don Juan era positivista. Sólo daba crédito a lo que observaba por medio de los sentidos y a las verdades matemáticas. De todo lo demás nada sabía, nada quería saber, hasta negaba la posibilidad de que nada se supiese. Era, no obstante, muy aficionado a las especulaciones y sistemas metafísicos, y le interesaban como la poesía. Los comparaba a novelas llenas de ingenio, donde el espíritu, la materia, el yo, el no-yo, Dios, el mundo, lo finito y lo infinito, son las personas que la fantasía audaz y fecunda del filósofo baraja, revuelve y pone en acción a su antojo ${ }^{1}$.

El positivismo de Juan Fresco, según parece, solamente toleraría la metafísica como una especie de creación artística o poética; lejos de explicar la realidad, la filosofía y el razonamiento especulativo quedarían relegados a una esfera distante y ajena, esfera dotada de una autarquía basada únicamente en la idealidad de la intuición estética.

1. Valera, J., Las ilusiones del doctor Faustino, Madrid, Librería de Fernando Fe, 1902, Introducción. 


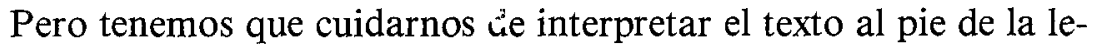
tra. La especulación matafísica como experiencia meramente estética es sin duda una formulación exagerada y precipitada. Valera no llegó nunca a tanto, como tampoco posiblemente llegaron a tanto, a pesar de las apariencias, Jorge Luis Borges ni su maestro Macedonio Fernández. Lo que Valera quiso decir es que la metafísica no posee el mismo grado de certeza ni pueden aplicársele las mismas exigencias de exactitud que a las ciencias positivas. Su realidad es de diversa índole, así como es de diversa índole la captación intelectual de sus verdades. Esta radical diversidad de la metafísica la emparenta con el arte; pero, lejos de rebajar la metafísica a mero fruto de la experiencia estética, eleva la experiencia estética al rango de la metafísica, como hemos de ver más adelante.

De la misma manera que la especulación metafísica es radicalmente diversa a las ciencias experimentales, también lo es el dominio de la religión, donde se impone igualmente un camino de captación de sus verdades que trasciende el raciocinio positivista. El mismo Juan Fresco que vimos transcendiendo los límites de las ciencias positivas merced a la especulación metafísica y a la experiencia estética, podrá igualmente elevar el vuelo a las verdades de la religión mediante una «intuición milagrosa»:

Don Juan, no obstante, distaba mucho de ser escandaloso ni impío. Aunque para él no había ciencia de lo espiritual y sobrenatural, esto no se oponía a que hubiese creencia. Por un esfuerzo de fe, entendía don Juan que podía el hombre ponerse en posesión de lo que el discurso no alcanza, y elevarse a la esfera súblime donde por intuición milagrosa descubre el alma misterios eternamente velados para el raciocinio ${ }^{2}$.

Tanto en el caso de la experiencia metafísica como en el de la experiencia religiosa, hay una intuición que permite trascender el estrecho marco que ofrece la ciencia positiva; esta intuición será «estética» en un caso, y «milagrosa» (religiosa, sobrenatural), en el otro. Lo que nos permite extraer una primera conclusión: la metafísica, el arte y la religión poseen un común denominador en esta superación del nivel empírico, y frecuentemente aparecerán las tres como perteneciéndose mutuamente y formando una esfera común, un mundo ideal. No poseen, sin embargo, la misma significación para Valera.

2 Ibíd. 
El arte, y muy especialmente la poesía, es sin duda la esfera ideal menos cuestionable: la intuición estética garantiza en todo momento su status de realidad ideal, y Valera piensa ante todo como poeta. La especulación metafísica ocupará el segundo lugar, siendo la captación de las verdades filosóficas explicada mediante la intuición artística, y no al revés. Y aunque la filosofía sea considerada por Valera, siguiendo a Aristóteles, como la más sublime (y la más inútil) de las ciencias ${ }^{3}$, no poseen las verdades filosóficas el mismo nivel de inmediatez que poseen las intuiciones artísticas, ni, esto es claro, les ha dedicado nuestro autor la misma atención. Las verdades de la religión constituirán un tercer grupo de la esfera ideal mucho más difícil de definir, sufriendo a través del tiempo grandes e importantes cambios, desde la imprecisa postulación de una «intuición milagrosa», como acabamos de ver, hasta la decidida afirmación de un Dios personal de orientación existencialista, pasando por un deísmo racionalista de corte volteriano y hasta por ciertos atisbos de experiencia mística.

Ahora bien, una vez expuesta la existencia de esta esfera ideal y su triple articulación, conviene resaltar que el punto de partida y la base que sustenta al núcleo de pensamiento de Valera es, como en el caso de Juan Fresco, el positivismo y el mundo de la experiencia sensible. Sea que el talante vital de nuestro autor le apegaba excesivamente a la realidad hic et nunc, sea que su extraordinaria inteligencia le obligaba a revisar continuamente sus postulados ideales, lo cierto es que en Valera la vertiente empírica, sensual y materialista volvía siempre por sus fueros para replantear nuevamente sus posiciones. Revisión continua, afirmación siempre renovada de la realidad material para, después de verificar sus límites, transcenderla de nuevo recurriendo a la esfera ideal.

Existe como un paralelismo entre el nivel material de la experiencia empírica y la esfera del ideal especulativo: por mucho que el ideal se perfeccione, nunca explicará por completo los fenómenos que analizan las ciencias positivas; y por mucho que se perfeccionen las ciencias positivas, tampoco podrán dar cuenta del mundo ideal, ni mucho menos sustituirlo o dictarle sus leyes. De esta manera, una y otra esfera parecen caminar paralelas sin poder encontrarse, sin llegar a una satisfactoria síntesis superior. Y aquí radica al escepticismo filosófico de Va-

Valera J., «La metafísica y la poesía», Obras Completas, tomo 36, Madrid, Imprenta Alemana, 1913, págs. 337 y 338. 
lera, escepticismo optimista y constructivo, pero escepticismo al fin y al cabo: la esfera ideal constituye siempre una apuesta por la interpretación transcendente. Esta apuesta deberá ser siempre renovada y replanteada de acuerdo con las dificultades que surgen de su concordancia con la experiencia, por lo que se trata, en definitiva, de una tarea imposible, o de una tarea sólo idealmente posible.

Testimonio de la limitación de las ciencias positivas es el siguiente párrafo, que no tiene desperdicio:

... El método empírico sirve para explicar los fenómenos y sus relaciones: para clasificar los seres y ponerlos como en un casillero; mas no para explicar las causas y elevarse a la metafísica, previamente desechada ${ }^{4}$.

Pero si las ciencias positivas no van más allá del método clasificatorio, tampoco es posible confiar en el dogmatismo especulativo, en una metafísica dogmática y definitiva. Valera distinguirá siempre entre una filosofía como «amor al saber» y una filosofía como «ciencia» en sentido estricto ${ }^{5}$, apoyando la primera y rechazando la segunda. Valera se queda con el concepto de filosofía que corresponde a su definición etimológica, y subrayará en repetidas ocasiones la necesidad de imponer el criterio de la modestia socrática. Es más, preferirá siempre la sinceridad de la duda a la hipocresía de los que fingen hipótesis:

No es fácil crear una metafísica, ni menos tenerla ya creada y ponerla como base. Caso de no tener ninguna metafísica, prefiero la sinceridad de la duda a la afirmación hipócrita de una creencia o de una ciencia de que se carece ${ }^{6}$.

Lo hasta aquí expuesto es suficiente para calificar el pensamiento de Valera de escéptico. Pero se trata de un escepticismo constructivo, un escepticismo dinámico y provisto de voluntad de superación. De la insuficiencia de las ciencias positivas no se desprende la necesidad de edificar una metafísica como ciencia estricta, perspectiva que considera Valera como ingenua y superada, pero sí la necesidad de construir un ideal capaz de esclarecer las preguntas más acuciantes del hombre, como son la naturaleza del alma, la idea de mundo o la de un principio absoluto de los seres.

4 Valera, J., «La religión de la humanidad», Nuevas Cartas Americanas, Madrid, Librería de Fernando Fe, 1890, págs. 242 y 243.

5 Krynen, L'esthétisme de J. Valera, Salamanca, Universidad de Salamanca, 1946, pág. 25.

6 Valera, J., «Psicología del amor», Obras Completas, tomo 35, Madrid, Imprenta Alemana, 1913, pág. 302. 
El escepticismo de Valera no niega la trascendencia de la esfera ideal ni aún cuando la postulación de dicha esfera no pase de ser un simple deseo, una añoranza o un «consuelo» metafísico:

Mi escepticismo es verdadero, esto es, que no niega, aunque no afirma tampoco; por donde allá en el centro del alma creo a veces mil cosas que algo me consuelan ${ }^{7}$.

Es más: dado que la verdad científica y la verdad poética no convergen en una unidad superior, de tener que elegir entre estas dos, Valera elegiría la verdad poética:

Il faut déplorer la divergence entre la verité poetique et la vérité scientifique. Ces deux vérités devraient converger. Mais, soyons francs: si elles ne convergent pas c'est que sur nombre de points, sur les plus interessants peut-être, la verité scientifique n'exite pas encore. L'imagination et la foi parviennent où la science ne parvient pas ${ }^{8}$.

Y si la esfera ideal es tenida como ilusoria y producto de la simple imaginación, no menos ilusoria parece ser la ciencia:

Ciertas ilusiones, que no lo son, no se pierden, pues, con la ciencia. Al contrario, la grande y efectiva ilusión está en creer que la ciencia mata lo que vemos con la fantasía o con la fe, calificándolo de ilusiones. Esta es una ilusión de la vanidad científica. Tal vez sea la más perjudicial de todas las ilusiones... ${ }^{9}$

Notemos que el tono desengañado y escéptico está igualmente dirigido a las disciplinas positivas y a las que no lo son, calificando a ambas de «ilusorias». Sin embargo, Valera se inclina por otorgarle a estas últimas mayor participación en la verdad.

El escepticismo de Valera es una especie de tensión o equilibrio siempre inestable entre las certezas incontrovertibles pero superficiales e insuficientes de la cosmovisión positivista, y los imperativos distantes e inalcanzables del ideal de lo absoluto. Ambos extremos son ilusiones, pero la exigencia de lo absoluto es una ilusión que confiere un sentido y justifica nuestro «amor a la sabiduría», y por tanto puede acercarnos, mediante una dialéctica infinita, a la verdad. Aun en caso de no

7 Pérez Gutiérrez, F., El problema religioso en la generación del 68, Madrid, Taurus, 1975, pág. 76.

8 Krynen, J., op. cit., págs. 23 y 24. La cita está tomada de «Verdades poéticas», Estudios críticos sobre religión y filosofía, tomo 35. El autor no da más datos.

9 Valera, J., Las ilusiones del doctor Faustino, ed. cit., Introducción. 
alcanzar jamás esta verdad, quedaría justificada su búsqueda en virtud de su mera idealidad, pues el hecho de intentar transcender el marco positivista constituiría ya de por sí el mayor ideal que nos sería dado realizar:

Aunque sin orden y por un arte vaga y sincrética, poseo o creo poseer cierta copia de verdades; algo como atisbos de filosofía perenne o, mejor dicho, como el germen y los primeros rasgos de tal filosofía, en el que concuerdan o se me antoja que concuerdan los entendimientos sanos. Armado de estos principios, como los héroes antiguos con sus penates, acudo a veces a refugiarme en el templo de la ciencia y entro en él lleno de religiosa veneración, confiado en los destinos y en la eterna vida de la divinidad simbólica que en él se adora. Si esta divinidad, si este símbolo no respondiese a nada real, sería al menos lo ideal y el más alto ideal del día presente ${ }^{10}$.

El escepticismo de Valera no puede ser comprendido sin relacionarlo con la doctrina de Kant. Incluso su tímida decisión de trascender el marco empírico tiene raíces en el autor de las dos Críticas, a quien Valera parece que leyó con atención y cuyo pensamiento expone con cierto lujo de detalles en diversos trabajos. Para Valera es fundamental tanto la doctrina de la Crítica de la Razón Pura, según la cual la idea del mundo no es más que el resultado de los datos formalizados por los esquemas de la sensibilidad y las categorías del pensamiento puro, como la Crítica de la Razón Práctica, según la cual es posible transcender estos esquemas de la sensibilidad y del entendimiento para llegar a las verdades transcendentales del Mundo, el alma del hombre y Dios. De la Crítica de la Razón Pura surge una consmovisión positivista limitada al mundo de la experiencia y ajena a las especulaciones metafísicas. De la Crítica de la Razón Práctica se deriva la posibilidad de superar el estrecho marco de las ciencias experimentales y dar el salto a la transcendencia. Dos mundos, dos cosmovisiones radicalmente opuestas, dos series perfectamente "paralelas» e independientes la una de la otra, como hemos visto al estudiar las ideas de don Juan Fresco. Y sin embargo, aunque el pensamiento de Valera parece inspirado en los principios del filósofo de Koenigsberg, no acepta el sistema de Kant por parecerle que los argumentos de la negación de la transcendencia en la primera Crítica invalidan los argumentos de la segunda:

Yo, no obstante, a fin de dar a Dios la existencia que en la Crítica de la Razón Pura casi le quita, adoptaría los argumentos de la Crítica de la Razón

10 Valera, J., «El racionalismo armónico», Obras Completas, tomo 35, Madrid, Imprenta Alemana, 1913, pág. 60. 
Práctica, si no fuera porque se me ha puesto en la cabeza, como trataré de probar más tarde, que, si valen las razones de la primera Crítica para negar, no sirven para para invalidarlas las razones de la segunda. Lo mejor es abstenerse de ser kantiano. ¿A qué propósito afirmar la existencia de Dios con pruebas que luego pareciesen ineficaces, teniendo que declararlo así por amor a la verdad? ${ }^{11}$.

La cita que antecede, perteneciente a «Metafísica a la ligera», encuentra el polo empírico demasiado negativo, pues desprovee de validez a todo argumento que no esté basado en la experiencia. Unas páginas más adelante propone Valera otro camino para llegar a la transcendencia: el de la introspección, donde se nos permite, ayudados por la inducción, descubrir una serie de verdades innatas que ya poseía nuestra alma, y que están en abierta contradicción con las ideas que proceden de la experiencia:

En resolución: Dios está sin duda en el alma; pero el alma no le ve ni le comprende, sino por sus efectos y sus obras. El alma llega a él por inducción, pero valiéndose de medios, de luces y de razones que tienen ya algo de lo infinito y de lo absoluto [...]. Ellas, a mi ver, están en el alma antes de la experiencia y conocimiento de las cosas particulares, y no vienen al alma por abstracción, ni por negación, sino inmediatamente de Dios mismo ${ }^{12}$.

No juzgamos necesario asignarle a esta doctrina el puesto que puede corresponderle entre las diversas teorías que registra la historia de la filosofía: ideas innatas de Platón, iluminación divina de S. Agustín, ontologismo de Malebranche, intuición de los valores de Max Scheler... Nos dispensamos de un análisis pormenorizado porque creemos que, en el fondo, se trata de una teoría ajena al espíritu eminentemente escéptico de nuestro autor. Leemos en un moderno estudio sobre Valera: «Así, contra Kant, Valera argumenta con la fe y el sentido común, y a sabiendas de que todo cuanto dice lógicamente no vale nada. [...] Da un salto Don Juan al terreno de la intuición, de la fe. Y aquí lo que importa es que nuestro autor, en el plano de los conceptos, va a defender algo que en su corazón no siente. Ya vimos cómo se confiesa escéptico. Defiende la fe sin tener fe ninguna» ${ }^{13}$.

11 Valera, J., «Metafísica a la ligera», Obras Completas, tomo 36, Madrid, Imprenta Alemana, 1913, pág. 60.

12 Ibíd.

13 García Cruz, A., Ideologías y vivencias en la obra de don Juan Valera, Salamanca, Ed. Universidad de Salamanca, 1978, págs. 67 y 68. 
Más importante sería analizar, no la doctrina que aquí se defiende sobre la posibilidad de alcanzar la transcendencia, sino los motivos que impulsan a Valera a criticar a Kant. Y éstos no son otros que la negación rotunda, en la Crítica de la Razón Pura, de la posibilidad de trascender la experiencia. Si Kant se hubiese contentado, en esta primera Crítica, con establecer los límites del pensamiento empírico en general, hubieran quedado abiertas las puertas a otro tipo de conocimiento que más tarde, en la Crítica de la Razón Práctica, podría legitimar el acceso a la metafísica.

Más equilibrado le parece el positivismo de un Littré o de un Spencer, quienes, sin renunciar a su credo de base positivista, dejan abierta una puerta a la posibilidad de transcenderlo:

Ya se ve que Littré, en sus momentos más lúcidos, se declara neutral: ni afirma ni niega. Pone lo sobrenatural fuera de nuestro alcance; por cima de nuestro raciocinio. Pero, ¿no habrá otras facultades de nuestra alma, por cuya virtud se pueda llegar a él? Yo veo que este positivismo agnóstico deja abierta la puerta a la imaginación, a la fe, o la intuición amorosa del alma afectiva, o quién sabe a qué otras facultades y potencias, para tender el vuelo y explayarse por ese infinito inexplorado, y apartar de él la desesperada calificación de incognoscible. De aquí que, en mi sentir, por el positivismo de Augusto Comte podamos volver de nuevo a las más fervorosas creencias... ${ }^{14}$

Comentando a Herbert Spencer, Valera llega a hacer del positivismo, paradójicamente, la condición misma de la especulación metafísica y de la experiencia religiosa, pues solamente las ciencias experimentales hacen al investigador consciente de su radical limitación:

De esta suerte, Herbert Spencer, que procede al principio como Augusto Comte, considerando la religión como superstición y puerilidad, vuelve reflexivamente a la religión después de haber recorrido toda la ciencia. Herbert Spencer funda esta segunda religión reflexiva, la religión de lo incognoscible, y aun la pone por encima de toda la ciencia: inexpugnable, invencible e indestructible ${ }^{15}$.

Las dos esferas que presenta Spencer (el mundo de la experiencia espacio-temporal regido por la ley de la causalidad y demás categorías a priori, y el mundo de las ideas transcendentes) son, básicamente, las mismas que acuñó el filósofo de Koenigsberg. La diferencia es una mera cuestión de matiz: Kant hace de ambas esferas mundos clausos, sin conexión entre sí. Spencer en cambio (y así lo entenderá el escepticismo

14 Valera, J., «La religión de la humanidad», ed. cit., pág. 225.

15 Id., pág. 239. 
constructivo de Valera), efectuará un salto desde las limitaciones y condicionamientos de la experiencia al dominio de lo ilimitado e incondicionado:

Para Herbert Spencer, tiempo, espacio, causa, substancia, movimiento, espíritu, son términos ininteligibles y llenos de contradicciones. No sabemos más que enlazar algunos fenómenos según la ley de la continuidad. Resulta, pues, al último extremo del empirismo baconiano y del positivismo comtiano, un profundo misterio religioso. Detrás de cada objeto, en el centro de cada cosa, en nosotros mismos, está lo incognoscible, y todo es efecto de su perpetua e incesante operación divina ${ }^{16}$.

Ahora bien: no debemos hacernos demasiadas ilusiones sobre este salto a la trascendencia. Don Juan Valera ha apostado muy tímidamente por la esfera ideal, y su idealismo peca de indecisión e imprecisión terminológicas. Nunca podemos saber con exactitud si su opitimismo obedece a una convicción auténtica. De las tres disciplinas que hemos señalado como pertenecientes a la «esfera ideal», solamente el arte y la poesía gozan de un decidido status de realidad metaempírica. Las verdades filosóficas ocuparán una posición incierta y de contornos desdibujados, en la cual solamente una especie de vaga intuición («atisbos») de la «filosofía perenne» guiará a la manera de ideal inalcanzable al «enamorado del saber». En cuanto a las verdades sobrenaturales, las vacilaciones de Valera, a las que aludiremos más tarde, sólo arrojan, en el mejor de los casos, un Dios consolador para los malos momentos, cuando no un principio vago e indeterminado que se acerca a la divinidad de los deístas del idealismo.

¿Habrá que entender el idealismo de Valera a la manera de los pragmatistas Lange o Vahihinger, para quienes la esfera del ideal, aunque dotada de innegable validez, no deja de ser una especie de como si sin mayor fundamento ontológico? ¿O podremos contentarnos simplemente con la noción de un idealismo fundado en una especie de «elegancia espiritual», es decir, fundado en el esteticismo? ¿Tiene la última palabra el Valera artista o el Valera intelectual?

De cuanto llevamos dicho se desprende que nuestra interpretación del Valera pensador se orienta a entenderlo como un pensador fundamentalmente escéptico, si bien su escepticismo posee ciertos atisbos de esperanza que le permiten apostar muy tímidamente por la superación del escepticismo. Antes de analizar con mayor detalle los aspectos con- 
cretos de este peculiar escepticismo, se nos permitirá exponer brevemente algunas interpretaciones que difieren total o parcialmente de nuestra exposición por minimizar este escepticismo o por subordinarlo a otras experiencias y viviencias espirituales.

A. Jiménez Fraud, en su brillante ensayo Juan Valera y la generación del 68 expone admirablemente el dilema al que se ve enfrentado nuestro autor: «Contra ambos dogmatismos, el de los hombres de ciencia y el de los hombres de fe, el secular y el eclesiástico, se rebela siempre el instinto liberal de Valera: tanto contra la infalibilidad, intolerancia y fanatismos teológicos, como contra la inevitabilidad, certidumbre y determinismo científicos; lo mismo contra la tiranía mental del espíritu, que según Valera perdió a España, y la nueva intolerancia ultramontana que culminó en la infalibilidad y en el principio de centralización de Roma, como contra el concepto materialista de la ciencia, que subordinaba toda la naturaleza (incluida la naturaleza humana), que creía sujeta a leyes ciertas, al dogmatismo político y a la tiranía del Estado».

Disentimos ligeramente de las ideas de este autor, quien sostiene que, «al adoptar esta actitud, que a uno y otro bando parecía anacrónica, Valera se anticipaba a la posición, actual hoy, de pensar que tanto creencias como sistemas participan de un principio común de incertidumbre que lleva lo mismo a científicos que a teólogos a sujetarse a una disciplina de observación y de experimentos, frente a los cuales la razón, libre de dogmatismos de una y otra clase, tenga el valor de aceptar la incertidumbre que sus propios límites le imponen, y la grave responsabilidad de elección personal que la vida racional le inflige. El temor a esta responsabilidad arrojó a los espíritus más pusilánimes a negar la realidad de la libertad; los más críticos encontraron refugio en el total escepticismo, y unos y otros terminaron por refugiarse en la sumisión a la autoridad. No aceptó esta derrota el espíritu de Valera: presenció la lucha, sufrió de ella, pero siempre combatió por la concepción clásica de la libertad humana, con aparato crítico en sus ensayos y con fina inspiración y arte en sus novelas» ${ }^{17}$. En nuestra opinión, la razón libre de dogmatismos y dispuesta a «aceptar la incertidumbre que sus propios límites le imponen», y que el autor adscribe al científico moderno, está muy lejos del escepticismo tal y como lo experimentó Vale-

17 Jiménez Fraud, A., Juan Valera y la generación del 68, Madrid, Taurus, 1973, págs. 136 y 137. 
ra. El investigador de la naturaleza, el físico atómico, el especialista en bioquímica, etc., lo mismo que, en la otra esfera, el filósofo o el teólogo, conocen muy bien el carácter relativo y provisional de sus hipótesis, y sin embargo «apuestan» por ellas en la convicción de haber contribuido, aunque en mínima parte, al progreso y clarificación de sus respectivos dominios. El espíritu moderno de incertidumbre, la convicción generalmente extendida de los límites de la razón humana, no impiden al científico investigar y experimentar, ni al filósofo o al teólogo especular. Y justamente la característica que más llama la atención en el escepticismo de Valera es que, una vez realizado el salto al ideal, hacia la transcendencia, nuestro autor se repliega en sí mismo, corrige posiciones, vuelve al punto de partida o «suspende» el juicio ante las dificultades de la empresa. Si su apuesta no fuese tan tímida (a veces tan insincera, tan sumisa a las convenciones de la época, o tan tornadiza y caprichosa), si Valera se hubiese decidido, como Unamuno, a realizar una apuesta existencial, habría superado su escepticismo sin por ello caer en el dogmatismo y sin renunciar al mínimo de incertidumbre caractetístico del espíritu científico del mundo moderno.

En una carta a Valverde de 14 de enero de 1860, expone Valera muy claramente la falta de firmeza de su «apuesta»:

Soy muy débil de carácter, como todo hombre más crítico que entusiasta. La literatura, la ciencia y la poesía me enamoran, son mi única pasión y sin embargo no me dedico a ellas, ni me atrevo a desterrarlas tampoco enteramente de mi pensamiento. Yo hago las cosas a medias, que es lo propio que no hacer nada. Feliz Vd. que tiene la fe que a mí me falta ${ }^{18}$.

La tendencia a minimizar la radicalidad del escepticismo de Valera la encontramos también, esta vez centrada exclusivamente en el problema religioso, en el libro de F. Pérez Gutiérrez El problema religioso en la generación del 68 . Su autor comienza negando categóricamente la afirmación de Azaña de que «Valera no era católico creyente, ni siquiera cristiano ${ }^{19}$, critica más adelante la opinión de Montesinos, en parte coincidente con Azaña, para quien las declaraciones de catolicismo de Valera «se acogieron como lo que eran, actos de oportunidad política» ${ }^{20}$, y llega a dar por sinceras, si bien dotadas de una cierta dosis de

18 Valera, J., Cartas inéditas a Gumersindo Laverde, Madrid, R. Diaz Casariego, 1984, pág. 39.

19 Pérez Guitérrez, F., op. cit., pág. 23.

20 Id. pág. 54. 
ironía, las tentaciones que tuvo Valera de «meterme fraile y de irme a predicar el Evangelio a la Oceanía o al centro de Africa» ${ }^{21}$.

Ciertamente, el autor de este libro no desconoce el alcance dubitativo de las protestas religiosas de Valera, a quien certeramente caracteriza como un creyente «sin ánimo para ilusionarse antes de tiempo, pero sin desazón para desistir de la esperanza» ${ }^{22}$. Lo malo de esta interpretación reside precisamente en dotar de igual peso específico a estas dos direcciones antagónicas, la del creyente y la del escéptico, postura que Pérez Gutiérrez formula muy precisamente con estas palabras: «En cuanto a su fe religiosa personal, fue un escéptico siempre tentado de creer, y un sincero - que no firme - creyente, siempre a dos pasos de vacilar, siempre, y a la vez, las dos cosas juntas» ${ }^{23}$. En nuestra opinión, el escepticismo, la duda, el combate, es lo que permanece. La superación de la duda - cuando esto tiene lugar - es una tímida apuesta que adquiere todas las características del consuelo metafísico o de la protesta vital que se enfrenta con el destino de la razón implacable y negadora de toda esperanza de salvación. Pero esta protesta no logra vencer por completo los imperativos de la razón, por lo que el amargo escepticismo se impone de nuevo. No son dos elementos de igual rango la fe y la duda, ni es posible imaginarse a Valera en este impreciso claroscuro de afirmaciones y negaciones. La duda o la suspensión del juicio gana el cambate porque es más radical. La fe es solamente una opción transitoria, como tendremos ocasión de ver.

En el brillantes estudio de J. Krynen $L$ 'esthétisme de $J$. Valera encontramos una tesis que defiende el origen del pensamiento de Valera. Según este autor, las ideas religiosas (y las ideas filosóficas) no son más que una derivación de su esteticismo: «L'esthétisme est le resultat de cette réduction de la philosophie et de la religion à l'art, en faveur de l'art: il exprime, hors de toute formule dogmatique, le pur appel du divin» ${ }^{24}$. Cuando Valera habla de religión o de filosofía, no hay que entender en su discurso una posición religiosa o filosófica determinada, sino un trasfondo artístico o poético: «Les affirmations d'apparence chrétienne que J. Valera formule sont, en effet, sécularisées: elles ont perdu

Id., pág. 26.

22 Id., pág. 95.

23 Id., pág. 96.

24 Krynen, J., op. cit., pág. 37. 
leur sens chrétien. De même qu'il parlait du krausisme et de la perfectibilité en poète, c'est en poète encore qu'il parle un langage chrétien» ${ }^{25}$.

Otras afirmaciones de Krynen son menos extremadas: no es la experiencia estética la que decide sobre el pensamiento (filosofía, religión), sino un agnosticismo de base que puede conducir, indistintamente, a la experiencia religiosa o a la vivencia puramente estética: «J. Valera connait alors un état d'agnosticisme pur, intermediaire entre une option esthétique possible et un desir de foi religieuse, un etat d'âme avec lequel il ne s'identifie point encore et qui pourrait le conduire aussi bien aux consolations poétiques qu'à celles du cloître» ${ }^{26}$. Pero, en general, domina en este estudio la idea de que es el esteticismo y no el agnosticismo o el escepticismo lo que define la ideología de Valera. La cita que sigue, encabezada por unas líneas del propio Valera, resume perfectamente esta interpretación: «A l'age de soixante ans, je me trouve sans science experimentale, sans connaissance des arts et sans métaphysique» (Carta-prólogo, Canciones, romances y poemas). «Cet apparent scepticisme signifie seulement que J. Valera est dans l'impossibilité de soutenir aucune doctrine objective qui forcerait l'adhésion des esprits, et non pas qu'il est dèpourvu de toute connaissance: il se dit poète et rien que poète. C'est ainsi que nous avons pu le voir distinguer la poésie de la science, et lui ouvrir un immense champ libre que la science ignore et où la poésie nous revelait les «vérités de l'avenir», et soutenir certaines doctrines auxquelles il n'adhérait qu'en poète, pour des raisons toutres personnelles, et qu'il n'est pas eloigné de considerer comme étant les seules vraies» ${ }^{27}$.

La interpretación de Krynen, en nuestra opinión, es desacertada. Krynen considera que el escepticismo de Valera es «aparente» porque cree que puede ser sustituido por el credo artístico y poético. De esta manera sería el esteticismo la explicación de su relativo escepticismo en cuestiones de religión y filosofía; el arte sustituiría a la ciencia, o, mejor dicho, sería el único medio verdadero de alcanzar el ser...

Nosotros opinamos que, justamente por ser el arte y la poesía una respuesta consoladora a las incertidumbres del pensamiento discursivo,
25 Id., pág. 35.
26 Id., pág. 38.
27 Id., pág. 43. 
presuponen la experiencia del fracaso de toda ciencia, toda metafísica y toda especulación teológica. El escepticismo es más originario que el credo esteticista, que no es más que un credo, al fin y al cabo.

Además, es dudoso que Valera haya encontrado consolación en el arte, a no ser una consolación pasajera. Como tampoco ha encontrado consolación en la filosofía ni en la religión, por muchos que hayan sido sus esfuerzos:

No hay filosofía, ni religión, ni tiquis-miquis de ningún género que de esto consuele. El mundo es malo, la vida peor, todos los países son insufribles [...]. Años ha que todos mis esfuerzos metafísicos se encaminan a ser optimista: pero a veces el pesimismo se apodera de mí sin poderlo yo remediar ${ }^{28}$.

Por lo demás, el libro de Krynen tiene el acierto de poner de manifiesto el parentesco entre la poesía (el arte), la filosofía y la religión, que, como ya hemos señalado, y conforme al planteamiento conflictivo de resonancia kantiana, son las únicas vías de acceso al ser por medio de la intuición o de la iluminación interior. Krynen lo comenta así, resumiendo:

Son oeuvre intéressera, au contraire, et au suprème degré, le philosophe et l'esthéticien parce qu'elle est un exemple vivant de conversion de l'état poétique en ontologie philosophique, qui le situe aux confins de la littérature, de la philosophie et de la mystique 29 .

Citemos aún otra teoría que pretende explicar el escepticismo de nuestro autor recurriendo a criterios ajenos al escepticismo mismo: García Cruz, en su libro Ideologías y vivencias de don Juan Valera, sostiene que el núcleo del escepticismo de Valera está fundado en la radical dicotomía entre su naturaleza vital y su naturaleza intelectual. Siguiendo al crítico italiano Mazzei, para quien «Il disaccordo tra intelletto e cuore, tra ideali filosofico-poetici e vita pratica, cioé, il fluttuare incerto tra l'ideale e il reale, senza posarsi ne nell'uno ne nell'altro, mostrano come ancora poco nutrita di convinzioni forti fosse l'anima sua... ${ }^{30}$, este autor extrae la conclusión de que la postura dubitativa de Valera expresa un dilema que se puede explicar solamente mediante el concepto de «ideología». En opinión de García Cruz, «lo vivido y lo expresa-

Pérez Gutiérrez, F., op. cit., pág. 77.

29

Krynen, J., op. cit., pág. 89.

Mazzei, «La lirica di Juan Valera», Bulletin Hispanique, XXVIII, 1927. Citado por García Cruz, op. cit., pág. 84. El autor no da más datos. 
do están en franca contradicción: y esto es muy significativo. Significa que Valera expresa una ideología, o sea que, para expresarnos en los términos más generales posibles, defiende un interés. Cuando la teoría se sustantiva y deja de promover una práctica, cuando ya no sabe organizar y orientar una actividad que tenía que salir de la propia entraña de su objetividad, se llama ideología [...]. Responde, de una manera general, a un interés. Y entonces se convierte en justificación» ${ }^{31}$.

No estamos de acuerdo en considerar que el pensamiento de Valera se «sustantive» (lo que implicaría, entre otras cosas, que se anulase la fecundidad creativa de la duda, de que tantas muestras ha dado), ni mucho menos podemos estar de acuerdo con la explicación simplista de que obedece al moderno concepto de una «ideología». García Cruz explica esta ideología mediante el recurso a la «presión social»: «Si en Valera el pensamiento no se encuentra radicado en su intimidad, en su vitalidad autoconsciente, hemos de buscarlo allí donde se origina el núcleo mismo de la contrariedad, en la presión social ${ }^{32}$. Pero entonces tendríamos un Valera incapaz de elevarse por encima de la sociedad de su tiempo, y no el espíritu libre que se anuncia en sus cartas y ensayos. Aunque no se puede negar el señoritismo andaluz de Valera, ni la superficialidad del diplomático mondain, la presión social, que evidentemente existe, se pone de manifiesto en otras esferas menos especulativas, como cuando don Juan esgrime el argumento de no chocar contra los usos y costumbres imperantes en la sociedad de su tiempo, y muy en especial contra las costumbres y los dogmas de la Iglesia oficial. Pero entonces resulta Valera consciente de esta actitud hipócrita y no la oculta a sus íntimos, como repetidas veces se pone de manifiesto en su epistolario. En su fuero interno, y descontando las inevitables influencias y presiones de la sociedad de su tiempo y de los convencionalismos del estamento diplomático, es Valera un intelectual libre y siempre dispuesto a someterlo todo a su espíritu crítico.

El mismo Valera se lamenta de que entre los progresistas y liberales no se encuentren intelectuales de la talla de los conservadores. Su acercamiento a estos últimos, acercamiento parcial y lleno de reservas, parece obedecer a motivaciones estéticas e intelectuales, en ningún modo a razones «ideológicas» en el sentido que García Cruz pretende. Destacamos un interesante párrafo de una de sus cartas a Menéndez Pelayo:

31 García Cruz, A., op. cit. pág. 83.

32 Id., pág. 85. 
Es raro que sean casi siempre, en España, los clericales, los neos o como queramos llamarlos, los acusados de parciales del oscurantismo, los que muestren en sus escritos más verdadera ilustración y más elegante cultura [...]. Aseguro a Vd. que no me explico por qué soy yo liberal en España. La gente culta no sé por qué está en los partidos más conservadores. Salvo Gabriel Rodríguez, Clarín y otros seis o siete, nadie gusta, ni lee, ni entiende de mis cosas en las huestes del liberalismo, cuyos jefes además me tratan pícaramente [...]. En fin, yo no puedo ser de otra manera que como soy; pero así como soy, cada día me son más simpáticos los oscurantistas que los liberales ilustrados ${ }^{33}$.

La misma postura dubitativa del escepticismo en general puede ser aplicada a su escepticismo religioso en particular, por lo que resulta muy aventurado saber cuál fue la última palabra de don Juan en punto a creencias religiosas.

Valera no fue un espíritu religioso. Su vitalidad desbordante, su estilo de vida de diplomático mundano, sus parentescos con la aristocracia y su frío racionalismo analítico, que todo ponía en tela de juicio, hacen sospechosa su religiosidad, aunque no imposible. Hay en Valera, más que una religiosidad determinada, distintos grados o estadios de religiosidad, sin que sea posible establecer una evolución temporal entre ellos.

Encontramos primeramente un estadio de religiosidad donde el extraordinario vitalismo de Valera hace derivar el amor a Dios del sentimiento egoísta del amor hacia nosotros mismos:

Si reflexionamos bien, el altruismo es sólo la expansión más o menos grande del egoísmo; es el amor que nos tenemos, y que se extiende a seres que vienen a quedar adheridos y como incluidos en nuestra personalidad. Por esto llamó un discreto al amor de dos amantes el egoísmo de dos; y asi pudiera llamarse el amor de la familia el egoísmo de seis o de diez, o de quince; y el amor de la patria, el egoísmo de veinte o treinta millones; y el amor de Dios hacia nosotros o de nosotros hacia Dios, el egoísmo total; aquel punto sublime en que egoísmo y altruísmo se confunden ${ }^{34}$.

Este estadio, aunque difícilmente pueda ser considerado como estrictamente religioso, es quizás el que más sinceramente sintió:

Yo soy en esto como el Aquiles de Homero, que amaba la vida por cima de todo y allá en el Orco le dijo a Ulises que daría toda su gloria inmortal por volver a vivir, aunque fuera un perro sarnoso. En fin, vida la vida y amémos-

Id., pág. 84.

Valera, J., «Psicología del amor», ed. cit., pág. 306. 
la, a pesar de todos los males. Sin este amor de la vida, ni los individuos ni los pueblos suelen hacen nada bueno ${ }^{35}$.

Este vitalismo es como la vertiente «positivista» de su religiosidad. Valera siente la necesidad de un Dios que le garantice la supervivencia de los sentidos y de la carne. Es como la proyección del instinto de vida.

Hay un segundo estadio o grado de religiosidad en que este vitalismo se acompaña de una racionalización progresiva del sentimiento religioso. Valera se acerca así a un vago deísmo optimista semejante al que defendieron algunos filósofos de la Ilustración; aunque no esté ausente de este deísmo la función consoladora de la religión, el optimismo de Valera encuentra razones basadas en el orden del cosmos, en la inteligencia de los seres, en el plan general del universo, etc., que le inspiran la idea de un Dios personal. En 1885, con ocasión de la muerte de su hijo, escribe Valera unas palabras a su mujer, de cuya sinceridad no podemos dudar:

Creer en la vida inmortal es la más poderosa consolación. Procura creer en ella. Yo, mientras más ahondo y reflexiono, menos irracional hallo la creencia. Hay tan enorme distancia entre el animal más inteligente y el ser humano más estúpido, que no acierto a atribuirla sólo al material organismo, y tengo que poner para explicármela otro elemento, distinto e imperecedero en nuestra esencia íntima ${ }^{36}$.

Una idea semejante leemos en otra carta, escrita en ocasión de su boda, en 1867:

Usted sabe que yo no soy indiferente en materias de religión. Soy tan apasionado como sujeto a dudas y vacilaciones, si bien me inclino al deísmo racionalista, al espiritualismo con la creencia en un Dios personal. Estas cosas, aún en vísperas de casarme, y aun en vísperas de morirme, absorben y absorberán siempre mi atención. Creo que tengo, a mi manera, un espíritu profundamente religioso, si bien cada día me separo más, allá en el fondo de mi conciencia, de la religión católica ${ }^{37}$.

Esta especie de deísmo encuentra su formulación más completa en el siguiente texto:

Hoy más que nunca, ya en la contemplación del universo visible, ya en la introversión del alma, en lo más hondo de su propio ser, se me aparece siempre algo de sustantivo, indivisible y único, en quien reside la fuerza que todo

35 Valera, J., Cartas inéditas a Laverde, ed. cit., págs. 205 y 206.

36 Pérez Gutiérrez, F., op. cit., pág. 76.

37 Id., pág. 54. 
lo hace, y la inteligencia que todo lo ordena, las cuales se advierten en cuantos seres conozco; pero no nacen en ninguno, ni brotan o emanan del conjunto de todos, ni son tampoco ser, sino atributos de un ser, sólo por sus obras conocido ${ }^{38}$.

En el artículo «La religión de la humanidad» abunda Valera en el mismo argumento, añadiendo ahora un comentario a las teorías de Sánchez Calvo que inciden en la creencia en un Dios-Fuerza y Dios-Consciencia:

\begin{abstract}
... Probar, en suma, que lo inconsciente de Hartmann, que es, en efecto, inconsciente para nosotros, es, por eso mismo, lo maravilloso, lo estupendo, lo certero, lo infalible, lo rico de providencia y de inteligencia, que mueve desde el átomo hasta el organismo más complicado: pero que este motor, de quien tal vez no tenemos consciencia los que por él somos movidos, la tiene él de sí y en sí, y lo penetra y lo llena todo, siendo al mismo tiempo todo y uno, porque si las demás cosas son algo, y si no son nada porque son él, es por el ser que él les da. En resolución, ese prurito de producir formas, vidas y evoluciones, esa energía constante de los seres que siguen inconscientemente su camino prescrito, y van a su fin en virtud de leyes indefectibles y eternas, es la incesante operación de lo inconsciente, el milagro perpetuo de lo que, siendo inconsciente para nosotros, es supraconsciente y es Dios ${ }^{39}$.
\end{abstract}

No es preciso multiplicar los ejemplos. Valera está aduciendo argumento caros al iluminismo francés, del que se declara rendido admirador. En una carta a Menéndez Pelayo anuncia Valera:

Paso por poco piadoso, y ahora tengo contraído el empeño de escribir un estudio sobre Voltaire ${ }^{40}$.

$Y$ hay pasajes enteros del gran pensador francés que podría suscribir enteramente Valera. Citemos un ejemplo extraído de L'ingénu de Voltaire: «Si je pensais quelque chose, c'est que nous sommes sous la puissance de l'Être Eternel comme les astres et les éléments; qu'il fait tout en nous, que nous sommes de petites roues de la machine immense dont il est l'âme; qu'il agit par des lois générales, et non par des vues particulières: cela seul me parait intelligible; tout le reste est pour moi un abîme de ténèbres" ${ }^{41}$.

Id., pág. 92.

Pérez Guitérrez, F., op. cit., pág. 55.

Valera, J., «La religión de la humanidad», ed. cit., pág. 266.

Voltaire, «L'ingénú», Romans et Contes, París, Garnier-Flammarion, 1966, cap. X. 
Pero hay un tercer grado o estadio de religiosidad en Valera en el que el optimismo de un deísmo racionalista deja paso a las inquietudes de la duda. A Valera le faltó auténtica convicción religiosa para sostener con su «razón vital» lo que probablemente eran construcciones artificiales dictadas en momentos de optimismo. Si comparamos sus confesiones de escepticismo con las protestas de religiosidad o con las construcciones un tanto artificiosas de su metafísica religiosa, comprobaremos en las primeras, además de mayor abundancia de textos, una mayor sinceridad y un acento personal (existencial, acaso) que está reservado exclusivamente a la intimidad epistolar. En 1885 dice Valera, criticando sus poemas de juventud:

Por desgracia mía, sin embargo, en esto del catolicismo yo soy como los gitanos, que si no la pegan a la entrada, la pegan a la salida; y así es que, con decir a lo último que la Humanidad se llenó de entusiasmo y llamó a Cristo hijo de sus entrañas, vengo a dar a conocer lo falso de mi $\mathrm{fe}^{42}$.

Pero acaso podamos matizar el descrecimiento de don Juan analizando algunos personajes de sus novelas. En El comendador Mendoza, el protagonista, casi un héroe de Nietzsche (equilibrado, liberal, incapaz de resentimiento, generoso hasta el sacrificio de su hacienda, fuerte, señor de su albedrío), es una figura por la que Valera no oculta su simpatía; es, de alguna manera, una transposición del personaje que a Valera mismo le hubiera gustado ser. Pues bien, de este personaje dice su amigo el padre Jacinto:

Bástete saber que yo tengo a don Fadrique por muy amigo, aunque incrédulo, como él me tiene por muy amigo, aunque fraile ${ }^{43}$.

En la novela Pasarse de listo, el protagonista de la novela, don Braulio, se suicida al final «porque tenía menos fe que un caballo» ${ }^{44}$. He aquí su confesión de escepticismo:

No acierto a entenderme directamente con Dios ni a desahogar con Él mis penas. Le busco en el abismo de mi alma, pero mi pensamiento se cansa y se asusta atravesando soledades infinitas sin llegar nunca a donde Él reside. Si yo no hubiese dejado de ser creyente, tendría mi confesor, quien lo sabría todo... ${ }^{45}$. 
Azaña, buen conocedor de Valera, y Bravo Villasante opinan que el don Braulio de Pasarse de listo es una transposición, aunque muy libre, del propio Valera ${ }^{46}$.

Hemos estudiado ya el personaje Juan Fresco de Las ilusiones del doctor Faustino, y su delicada ambigüedad propia del escéptico. En otras novelas el protagonista es creyente, pero el autor ironiza y a veces casi ridiculiza la vertiente mística de su pensamiento, como sucede en la tan injustamente famosa Pepita Jiménez o en su obra más perfecta y casi olvidada por la crítica literaria, Doña Luz.

Creemos que las citas hasta aquí aportadas son suficientes para probar que el escepticismo religioso es, en Valera, lo suficientemente flexible como para excluir cualquier interpretación definitiva. Una total negación de la trascendencia está por completo ausente de su obra, como también está ausente la afirmación decidida y consecuente. En esto justamente consiste el verdadero escepticismo, esto es, la suspensiń del juicio y de la afirmación rotunda. Hay, sin embargo, matices o grados en este escepticismo, como creemos haber mostrado; y dado que ninguno de estos grados puede ser clasificado y reducido a un esquema evolutivo, quedan en lo que son: manifestaciones dubitativas e inseguras fruto del espíritu crítico de su autor. Creemos que en nuestro tiempo, y después de publicadas varias colecciones de su epistolario, ya no es posible opinar como Juan de Zaragüeta, para quien «la metafísica de don Juan Valera termina con una afirmación de rotunda religiosidad» ${ }^{47}$; o como Gerhard Engel, para quien Valera nunca habia dudado de la existencia de Dios ${ }^{48}$. Un par de consultas al epistolario de Valera hubiera bastado para que estos autores mudaran de opinión. Valga como ejemplo un fragmento de una carta a Valverde de 8 de agosto de 1867:

En el alma agradezco a Vd. el interés vivo que me muestra y la buena calificación que hace de mi fastidio y malestar, llamándole «hambre de Dios». No quiero ser hipócrita con Vd. Prefiero ser franco, aunque pierda mucho en su concepto. Yo no tengo hambre de Dios, sino hambre de dinero, de goces terrenales y de bienestar en este bajo mundo. El único mérito que hay en mí

46 Pérez Gutiérrez, F., op. cit., pág. 72. Azaña, M., «Prólogo a Pepita Jiménez», Madrid, Espasa-Calpe, 1971, pág. LVIII.

47 García Cruz, A., op. cit., pág. 36.

48 Engel, G., Don Juan Valera. Weltanschauung und Denkverfahren, Wuerzburg, R. Mayr, 1935, págs. 165 y 166. 
es el de no querer hartar esta hambre a costa de ninguna picardía, de ninguna humillación y de ninguna bajeza; pero, al mismo tiempo, la virtud sola no me satisface y por eso rabio y me lamento ${ }^{49}$.

Tocaremos un último punto relacionado con el escepticismo de Valera: su concepción de la metafísica.

Valera no es filósofo, ni siquiera estudioso sistemático de la filosofía. Pero no carece de interés su opinión sobre la filosofía. El esteta y artista que fue Valera echó mano en repetidas ocasiones de temas filosóficos y hasta metafísicos. En un artículo en que polemiza con Ramón de Campoamor para criticar la concepción de éste sobre «lo absoluto», dice Valera:

Quiero que no profanemos el nombre de filosofia; pero, en esta ocasión, impulsado por el ejemplo de usted, y sólo como mero aficionado, confieso que me decido a filosofar; que tengo conatos de filosofía, si bien no pasan de conatos, si bien sea un delito frustrado mi ensayo crítico-filosófico... ${ }^{50}$

¿Qué concepto tiene Valera de la filosofía, $y$, de manera especial, de la metafísica? En un interesante ensayo en forma dialogada titulado «El racionalismo armónico», dice Valera, criticando la filosofía positivista, lo que entiende por verdadera tarea filosófica:

Aun dando por seguro que el saber de observación fuera ya tan extenso que todo lo comprendiese, todavía, al menos yo lo veo así, de nada de esto, ni de nosotros mismos, conoceríamos, sino atributos y cualidades, cuya suma no alcanzaríamos, $y$, aun alcanzada, no nos daría la impenetrable, íntima y misteriosa esencia de ser alguno.

Por otra parte, la ciencia fundamental y los resultados de la experiencia no veo yo, a no valerme de sofismas, que se ajusten y compenetren, formando un todo de saber armónico ${ }^{51}$.

En estas apretadas líneas están contenidas las dos condiciones básicas que debe cumplir la ciencia primera: tratar de la esencia de los seres y no de sus cualidades accidentales, como es el caso de las ciencias positivas, que todo lo reducen a magnitud y datos cuantificables, y formar un conjunto de conocimientos universales aplicables a todos los seres. Estas dos características, que se implican mutuamente, están presentes

49 Valera, J., Cartas inéditas a Laverde, ed. cit. carta del 8-VIII-1867.

so Valera, J., Cartas al señor don Ramón Campoamor sobre su libro de lo absoluto», Obras Completas, tomo 35, Madrid, Imprenta Alemana, 1913, pág. 13.

51 Valera, J., «El racionalismo armónico», ed. cit., pág. 134. 
en la filosofía occidental desde, por lo menos, su formulación en los libros IV y VI de la Metafísica de Aristóteles. No cabría esperar mayor originalidad de la pluma de Valera en una materia que, evidentemente, no era la suya. Pero de mayor interés resulta la aplicación de estas características a la filosofía positivista y al espíritu positivista de la época:

Ignoraré quizás para siempre lo que es la substancia; permanecerá oculto para mí el por qué y el cómo de esos seres: pero lo que es el cuánto, merced a las Matemáticas, lo sabré con exactitud maravillosa. Nada más claro, más bello, más grande a nuestros ojos que el sol. Y sin embargo, lo mismo el ignorante que el sabio, todos ignoramos lo que es, cómo es y por qué es. Ni de su substancia, ni de sus cualidades esenciales sabemos nada [...]. En suma, yo creo que a todas las preguntas que digan ¿cuánto?, se responde o puede responderse, pero casi nunca hay sabio que responda a un ¿por qué?, a un ¿cómo?, a un ¿qué es eso? Si da respuesta viene a ser la pregunta misma con diferentes términos. La duda, la obscuridad, no se disipa. ¿Por qué hace dormir el opio? Por qué hay en él una «virtud dormitiva»? Esta contestación del personaje ridículo de Molière y la del más sabio naturalista, químico o médico, se diferencian poco ${ }^{52}$.

Como hemos apuntado anteriormente, el escepticismo de Valera, como el de Juan Fresco, apuesta por trascender el miope punto de vista del positivismo:

No hay nada, además, por especulativo y poco práctico que aparezca, que no suscite en esta ciencia el interés más profundo en todo ser humano. Nuestro origen, nuestro destino, nuestro último fin, van envueltos en la demostración de sus teoremas ${ }^{53}$.

Y Valera repetirá en varias ocasiones la célebre frase de Aristóteles de que «toda ciencia es más útil que la filosofía, pero ninguna es más sublime» ${ }^{54}$.

Pero si por una parte la filosofía pretende conocer la esencia indemostrable, y por otra parte no hay tarea más difícil de alcanzar que esta superación de lo cuantificable y accidental que constituye la especulación positivista, el concepto de filosofía de Valera se acerca mucho a un ideal inalcanzable, a una tarea casi imposible y cuyos planteamientos constituyen más una dirección ideal de nuestro pensamiento que un saber alcanzable y perfeccionable en lo concreto. Entre la postura del gracioso de Molière, para quien toda explicación de la esencia de un ser

Id., pág. 113.

Id., págs. 119 y 120.

Valera, J., «La metafísica y la poesía», ed. cit., págs. 337 a 339. 
descansa en la panacea de una «virtus occulta», y la postura de los que se contentan con una respuesta de tipo matemático y cuantificable, parece que no hay más camino que postular la idealidad de la búsqueda filosófica:

... Yo no afirmo la existencia de una metafísica inconcusa, evidente y sola, sino su necesidad para que funde la ciencia y haya ciencia; y lo conveniente de esta metafísica, como aspiración, como amor, , como reclamo y señuelo, que mueva las alas de la mente y la atraiga y levante hacia las grandes verdades ${ }^{55}$.

La metafísica así concebida, además de servir de guía a las ciencias particulares «como la columna de fuego que guiaba a los hebreos en el desierto» ${ }^{56}$, tiene también la función de poner un freno a la «manía demoledora del saber empírico»:

La metafísica, hasta la más escéptica y crítica, en vez de demoler, pone freno a la manía demoledora del saber empírico, y, sobre todo, eleva el alma al ideal, aunque le deje como ideal vacío y sin realidad objetiva ${ }^{57}$.

En definitiva, la búsqueda de la verdad es más importante que la verdad misma:

En vez de quejarme con Leopardi, propendo a decir con Lessing que lo divertido no es hallar la verdad, sino buscarla, y que si Dios me pusiese en una mano la verdad, y en otra el poético anhelo y la amena tarea de ir en su busca, me quedaría con lo segundo ${ }^{58}$.

Acaso el mejor ejemplo que pone de manifiesto este difícil equilibrio entre el total escepticismo y su opuesto, el dogmatismo metafísico, sea el tema de la sustancia. Valera considera la pregunta por la sustancia como medular en toda especulación metafísica; pero no acierta a dar una respuesta definitiva. Se contenta con decir lo que no es sustancia, con lo que este concepto, equidistante entre la total ignorancia y la certeza absoluta, ocupa un puesto intermedio capaz de seducir y espolear al investigador para que perfeccione su noción mediante una especie de dialéctica infinita:

55 Valera, J., «Metafísica a la ligera, ed. cit., pág. 14.

56 Id., pág. 16.

57 Id., pág. 47.

58 Id., pág. 77. 
Dice muy bien el Sr. Campoamor cuando dice: «La noción de sustancia es la única cuestión fundamental: todas las demás son secundarias. El que ve con claridad la noción de sustancia lo ve todo; el que la ve turbiamente, no ve nada. Sin vencer esta dificultad, no hay victoria en filosofía». Repito que dice bien el sr. Campoamor, pero por lo mismo me he retraído yo siempre de filosofar dogmáticamente, y me he contentado con ser un mero crítico negativo. Yo no veo clara la noción de substancia. Creo que hay substancia, pero ignoro en qué consiste. Lo propio le pasa al sr. Campoamor, salvo una diferencia, a saber: que él afirma y yo me abstengo de votar; que él yerra y yo no digo nada de positivo ${ }^{59}$.

Naturalmente, esta falsa modestia de corte socrático esconde más de lo que parece. Si Valera no sabe qué es la substancia, por lo menos conoce opiniones erróneas acerca de ella, y además de criticar las peregrinas interpretaciones de Campoamor, pasa igualmente revista, en este mismo artículo, a las de Pitágoras (apoyándose en la crítica de Aristóteles), Newton y Hegel, que tampoco le satisfacen por diluir la substancia en cantidad.

No es mucho lo que ha dejado escrito Valera en torno al pensamiento especulativo, el arte o la religión. Tampoco es necesario reprochárselo a quien tiene méritos sobrados para ser uno de nuestros mejores prosistas en lengua castellana. Lamentamos que la exposición de sus ideas filosóficas o religiosas haya estado con frecuencia envuelta en polémicas con escritores y pensadores muy celebrados en su tiempo (Castelar, Campoamor...), que hoy no dejan de parecernos de suma mediocridad. Culpable es el entorno cultural que le cupo en suerte vivir, y que le hizo exclamar en más de una ocasión frases lapidarias como la de que «sospecho mucho que siempre ha sido esta tierra tierra de garbanzos y no de filósofos» ${ }^{60}$.

59 Valera, J., «Cartas al señor don Ramón de Campoamor sobre su libro de lo absoluto», ed. cit., pág. 43.

60 Valera, J., Cartas inéditas a Gumersindo Laverde, ed. cit., pág. 66. 